\title{
Is there life after medicine?
}

$\mathrm{F}$ or some, retirement is a relief - rounds of golf interspersed with naps and other luxuries like the time to read a novel.

Others miss the camaraderie of the workplace and the sense of purpose their careers provided.

Doctors are no exception in either category, says retiree Dr. Ashok Muzumdar. "I find some physicians, males and females, do not quite enjoy their life to the fullest after retirement. It's like falling off a cliff. They're finished practicing medicine, now what?"

In a bid to help those who might fall within that latter category, Muzumdar is spearheading the development of a Canadian Society of Retired Physicians which might serve a variety of purposes, including a vehicle for mentoring, a forum to exchange ideas and concerns about the changing medical landscape, and even social gatherings.

Muzumdar says he's now canvassing Canada's estimated 9000 retired physicians to see if they might be interested in forming the Canadian equivalent of the United Kingdom's Retired Fellows Society, (a section of the Royal Society of Medicine).

The UK society, now in its 12 th year of operation, serves as an excellent vehicle for retirees to keep in touch with one another, writes Dr. Pat Last, past immediate chairman, in an email. "Once retired, one's interest in the current medical scene wanes and one is more interested in keeping touch with colleagues."

To that end, the Royal Fellows Society organizes lecture luncheons and outings focused on an eclectic variety of topics within medicine, science, history and the arts.

Muzumdar hopes that a Canadian society might serve a similar social purpose, while also providing a vehicle for retirees who'd like to keep making a contribution to Canadian health care, by say, mentoring residents or young physicians, or becoming involved in policy development.

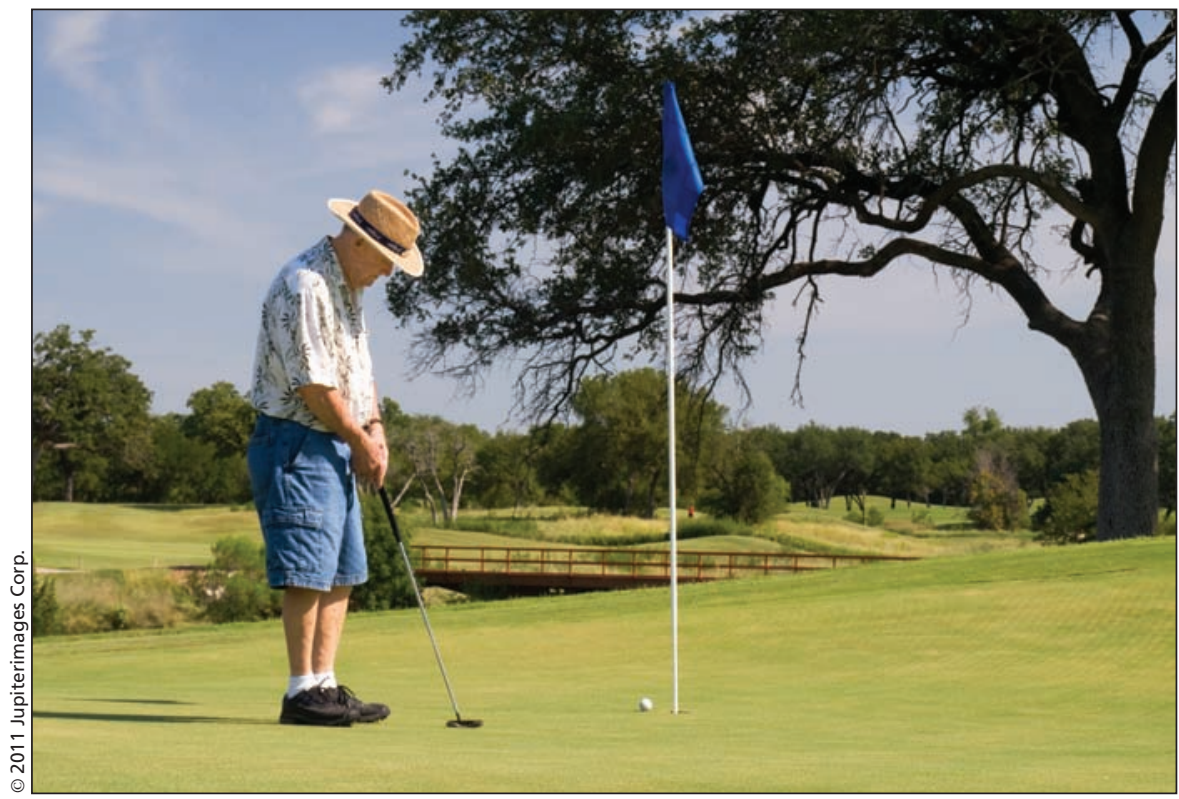

It seems that some retired physicians believe that they can play only so many rounds of golf.

Canada's geography is an obstacle, Muzumdar admits. The 1200 members of the UK society are concentrated in an area approximately 40 times smaller than Canada, and even distant members can readily attend luncheon gatherings.

But the problem of distance isn't insurmountable, says Dr. Eugene Nurse, acting chair for the senior and retired doctors section within Doctors Nova Scotia, the only organized body in Canada for retired physicians.

"It's amazing that we don't have [a national association] already," Nurse says. "The British have one, and goodness, we take everything we have from the Brits!"

It's hoped that some of the geographic obstacles can be overcome through the use of information technologies and to that end, Muzumdar is working with John Feeley, director, members and provincial territorial medical associations, in the Canadian Medical Association's department of community building, to explore how the Internet might be used to expand awareness of the embryonic effort to create a national association of retired physicians.

The problem, Muzumdar says, is that many retired physicians of his generation aren't altogether familiar with electronic tools. Nurse says that during the Nova Scotia association's formative years, traditional (standard mail, rather than email) communication methodologies had to be used to get the word out to some. But once word spread, the response was enthusiastic, he says.

Muzumdar says that before officially launching an association, he hopes to attract a base group of 50-60 retirees who can help with the spadework, including fleshing out the range of activities it might offer: mentoring of younger physicians, reading clubs, golf or travel clubs.

The value of, and need for, a retirees association will become ever greater as the baby boom generation retires, Mumzumdar says, adding that it would be a waste for society to turn their backs on a resource that isn't now being used to its potential. "I' $m$ just one among thousands who could be very useful to different facets of post retirement life," he adds. - Sabrina Doyle, Ottawa, Ont.

CMAJ 2011. DOI:10.1503/cmaj.109-371 